\title{
PENGARUH MODEL PEMBELAJARAN KOOPERATIF LEARNING BERBASIS MEDIA INTERAKTIF DAN KOMUNIKASI INTERPERSONAL TERHADAP HASIL BELAJAR PENDIDIKAN AGAMA ISLAM
}

\author{
Catur Ayu Wulandari', Efendi Napitupulu', Keysar Panjaitan ${ }^{3}$ \\ ${ }^{I}$ SD Negeri di Kelurahan Siumbut-Umbut, Asahan, ${ }^{2,3}$ Pascasarjana Universitas Negeri Medan \\ w0elan@ymail.com ${ }^{l}$
}

\begin{abstract}
Abstrak: Penelitian ini bertujuan untuk mengetahui: Apakah hasil belajar pendidikan agama Islam siswa yang dibelajarkan dengan model jigsaw lebih tinggi daripada hasil belajar pendidikan agama Islam yang menggunakan model make and match, Apakah hasil belajar pendidikan agama Islam siswa yang memiliki komunikasi interpersional tinggi lebih tinggi daripada hasil belajar pendidikan agama Islam yang memiliki komunikasi interpersional rendah, Apakah terdapat interaksi antara model pembelajaran dan komunikasi interpersonal terhadap hasil belajar pendidikan agama Islam siswa. Penelitian ini dilakukan pada siswa SD. Teknik pengambilan sampel digunakan dengan Cluster Random Sampling berdasarkan masing-masing terdiri dari 30 untuk kelas ekperimen pertama dan 30 orang untuk kelompok ekperimen kedua. Metode penelitian yang digunakan adalah quasi eksperimen dengan factorial $2 \times 2$. Teknik analisa yang digunakan adalah analis varians dua jalur dengan taraf signifikan $\alpha=5 \%$ dengan Uji $F$, pengujian lanjut menggunakan Uji Scheffe. Hasil penelitian menunjukkan: hasil belajar Pendidikan agama Islam siswa yang ajar dengan model pembelajaran Jigsaw lebih tinggi daripada pembelajaran model Make and Match dengan nilai $F_{\text {hitumg }}>F_{\text {tabel }}$. dengan nilai $F_{\text {hitung }} 12.94>F_{\text {Tabel }} 4,00$, hasil belajar pendidikan agama Islam siswa yang memiliki Komunikasi Interpersonal tinggi lebih tinggi daripada hasil belajar siswa yang memiliki komunikasi interpersonal rendah dengan nilai $F_{\text {hitung }}=11.86>F_{\text {tabel }}=4,00$, terdapat interaksi antara Model Pembelajaran dan komunikasi interpersonal dalam mempengaruhi hasil belajar pendidikan agama Islam dengan nilai $F_{\text {Hitung }}$ kolom - baris (interaksi) lebih besar dari $F_{\text {tabel. }} F_{\text {hitung }}=10,39>F_{\text {tabel }}=4,00$ pada taraf signifikansi 5\%. Dengan demikian semakin baik model pembelajaran yang digunakan dalam pembelajaran, maka semakin tinggi hasil belajar siswa dalam pembelajaran pendidikan agama Islam, atau semakin tinggi komunikasi interpersonal siswa dengan model Jigsaw, maka semakin tinggi hasil belajar yang diperoleh siswa interaksi antara model pembelajaran dan komunikasi interpersonal akan memberikan dampak positif dalam hasil belajar.
\end{abstract}

Kata Kunci: model pembelajaran, komunikasi interpersonal dan hasil belajar pendidikan agama islam.

\begin{abstract}
This study aims to determine: Is the result of learning Islamic religious education students using jigsaw model is higher than the result of learning Islamic education using make and match model Based on interactive media, Is the result of learning Islamic religious education students who have High interpersional communication is higher than the result of learning of Islamic education which has low interpersional communication, is there any interaction between model of learning and interpersonal communication to result of learning of Islam religion student. This research was conducted on Elementary School. The sampling technique was used with Cluster Random Sampling based on each of 30 for the first experimental class and 30 for the second experimental group. The research method used is quasi experiment with factorial $2 \times 2$. Analytical technique used is a two-lane variance analyst with a significant level $\alpha=5 \%$ with $F$ test, further testing using Sccheffe Test. The result showed that : the learning result of the Islamic Religious Education students who were given the Jigsaw learning model is higher than the learning model of Make and Match with $F_{\text {count }}>F_{\text {table }}$ value. With value $F_{\text {count }} 12.94>F_{\text {table }} 4.00$, the result of learning Islamic religious education students who have high Interpersonal Communication is higher than student learning outcomes that have low interpersonal communication with the value $F_{\text {count }}=11.86>F_{\text {table }}=4.00$, (3) there is interaction between Learning Model and interpersonal communication in influencing the result of learning of Islamic education with the value of $F_{\text {count }}$ column - the interaction is bigger than $F_{\text {table }}\left(F_{\text {count }}=1.39>F_{\text {table }}=\right.$ 4.00) at significance level 5\%. There is the better the learning model used in learning, the higher the learning outcomes of students in learning Islamic religious education, or the higher interpersonal student communication with Jigsaw model, the higher the learning outcomes obtained by students interaction between learning models and interpersonal communication will provide Positive impact in learning outcomes.
\end{abstract}

Keywords: learning model, interpersonal communication and learning outcomes islamic religious education. 


\section{PENDAHULUAN}

Suatu tujuan pembelajaran menyatakan suatu hasil yang diharapkan dari pembelajaran itu dan bukan sekedar suatu proses dari pembelajaran itu sendiri. Tuntutan manusia yang berkualitas hanya dapat dipenuhi oleh dunia pendidikan. Upaya pemenuhan tersebut merupakan suatu proses yang panjang yang dimulai sejak anak belajar di SD. Salah satu unsur yang turut menentukan kualitas Sumber Daya Manusia yaitu Pendidikan Agama Islam Salah satu mata pelajaran yang ada di SD yang perlu ditingkatkan kualitasnya adalah agama dan SD merupakan tempat pertama siswa mengenal konsep-konsep dasar agama, karena itu pengetahuan yang diterima siswa hendaknya menjadi dasar yang dapat dikembangkan di tingkat sekolah yang lebih tinggi disamping mempunyai kegiatan praktis yang dapat diterapkan dalam kehidupan sehari-hari.

Pada pembelajaran Pendidikan Agama Islam sangat berkaitan dengan dunia nyata dalam kehidupan sehari-hari. Guru dapat membuka berbagai pikiran dari siswa yang bervariasi sehingga siswa dapat mempelajari konsep-konsep dalam pengamalan pada aspek yang terkandung dalam mata pelajaran Pendidikan Agama Islam untuk memecahkan suatu masalah atau persoalan serta mendorong siswa membuat hubungan antara materi Pendidikan agama Islam dan penerapannya yang berkaitan dalam kehidupan sehari-hari.

Pendidikan Agama Islam merupakan konsep dasar Islam yaitu pembelajaran keyakinan dan mempunyai hubungan yang sangat luas terkait dengan kehidupan manusia. Pembelajaran Pendidikan Agama Islam sangat berperan dalam proses pendidikan dan juga perkembangan akhlak, karena Pendidikan Agama Islam memiliki upaya untuk membangkitkan minat dan motivasi siswa serta kemampuan dalam mengembangkan pemahaman serta dikembangkan menjadi ilmu pengetahuan agama yang dapat diterapkan dalam kehidupan sehari-hari. Menurut Majid dan Andayani (2009:132) Pendidikan Agama Islam adalah suatu usaha sadar yang dilakukan pendidikan dalam rangka mempersiapkan peserta didik untuk meyakini, memahami dan mengamalkan ajaran agama Islam melalui kegiatan bimbingan, pengajaran atau pelatihan yang telah ditentukan untuk mencapai tujuan yang telah ditetapkan.

Kurikulum pendidikan Islam bersumber dari tujuan pendidikan Islam. tujuan pendidikan agama Islam adalah merealisasikan manusia Muslim yang beriman, bertakwa dan berilmu pengetahuan yang mampu mengabdikan dirinya kepada sang Khalik dengan sikap dan kepribadian bulat menyerahkan diri kepada-Nya dalam segala aspek kehidupan dalam rangka mencari keridhaan-Nya. Abdullah, (2014:41). Tujuan yang akan dicapai dari kurikulum pendidikan Islam adalah membentuk anak didik berakhlak mulia dalam hubungannya dengan hakikat penciptaan manusia. Sehubungan dengan kurikulum pendidikan Islam

Berdasarkan hasil observasi yang telah dilakukan oleh peneliti di kelas V SD SiumbutUmbut Kisaran diperoleh hasil belajar siswa masih rendah. Persentasi siswa tuntas hanya $50 \%$ dari 120 siswa dan untuk siswa seluruhnya diperlukan remedial. Masih banyak siswa yang memperoleh nilai di bawah nilai standar kelulusan KKM yaitu 73. Rendahnya kualitas hasil belajar siswa tersebut dapat disebabkan oleh banyak faktor. Faktor-faktor yang mempengaruhi hasil belajar digolongkan menjadi dua, yaitu faktor eksternal dan faktor internal (Slameto, 2009:54). Adapun yang dimaksud dengan faktor eksternal adalah segala faktor yang berasal dari luar diri siswa seperti faktor keluarga, faktor sekolah dan faktor masyarakat. Dalam hal ini rendahnya hasil belajar Pendidikan Agama Islam siswa apabila ditinjau dari sisi eksternal siswa salah satunya berkaitan dengan sekolah sebagai lembaga pendidikan yang merupakan sumber informasi formal yang sangat penting bagi siswa. Faktor sekolah sangat menentukan keberhasilan belajar siswa dan beberapa faktor yang mempengaruhi hasil belajar dalam lingkungan sekolah mencakup model pembelajaran, kurikullum dan media pembelajaran dan waktu di sekolah. Oleh sebab itu, perlu pengkajian khusus salah satunya mengenai model pembelajaran yang digunakan. Apakah model pembelajaran tersebut sesuai dengan konteks materi dan tujuan pembelajaran, potensi dan latar belakang siswa serta konteks dengan situasi dan lingkungan belajar. Oleh karena itu, guru memiliki peran yang sangat penting terutama yang menyangkut model pembelajaran yang digunakan dalam proses belajar yang juga akan ikut menentukan 
tinggi-rendahnya hasil dan tercapainya tujuan pembelajaran Pendidikan Agama Islam.

Berdasarkan identifikasi masalah yang dilakukan pada observasi awal salah satu penyebab terjadinya kesenjangan ini adalah kurang variatifnya model pembelajaran yang digunakan oleh guru. Suasana belajar di dalam kelas yang terlalu serius dan terkesan membosankan akibat model pembelajaran yang diberikan guru kurang bervariasi padahal pendidikan Pendidikan Agama Islam perlu diberikan dengan lebih hidup kepada siswa. Murid tidak cukup dijejali kesibukan kognitif, menghapal pengetahuan lewat fakta-fakta, sebagaimana banyak terjadi selama ini.

Untuk menggali potensi anak agar selalu kreatif dan berkembang perlu diterapkan pembelajaran bermakna yang akan membawa siswa pada pengalaman belajar yang mengesankan. Pengalaman yang diperoleh siswa semakin berkesan apabila proses pembelajaran yang diperoleh merupakan hasil dari pemahaman dan keyainannya sendiri yaitu proses yang melibatkan siswa sepenuhnya untuk merumuskan suatu konsep. Untuk itu sudah menjadi tugas guru dalam mengelola proses belajar-mengajar adalah memilih model pembelajaran yang sesuai, agar pembelajaran lebih menarik dan bermakna.

Hal ini disebabkan adanya tuntutan pada dunia pendidikan bahwa proses pembelajaran tidak lagi hanya sekedar menstransfer pengetahuan dari guru ke siswa. Guru harus mengubah paradigma tersebut dengan kegiatan pembelajaran yang aktif, kreatif, efektif dan menyenangkan. Terkait belum optimalnya hasil belajar siswa kelas V SD Siumbut-Umbut Kisaran, maka penulis berupaya menerapkan model pembelajaran yang sepenuhnya dapat melibatkan siswa secara aktif dalam kegiatan pembelajaran. Mungkin akan berbeda hasil pembelajaran bila pembelajaran Pendidikan Agama Islam dilakukan dengan menggunakan model pembelajaran Jigsaw sebagai salah satu alternatif pembelajaran yang bermakna yang bermuara pada pembelajaran yang aktif, kreatif dan menyenangkan.

Jigsaw) merupakan salah satu teknik dari model pembelajaran Kooperatif Learning. Model pembelajaran ini pertama kali dikembangkan oleh Elliot Aronson, dkk di Universitas Texas. Dan kemudian di adaptasi oleh slavis dan teman-temannya di Universitas John Hopkins (Trianto, 2006:71). Ini menjadi salah satu pilihan bagi guru, yaitu dalam menyikapi perkembangan zaman, terutama dalam paradigma pembelajaran yang kini diarahkan pada pendekatan siswa sentries yang menekankan pada proses.. Teknis pelaksanaannya hampir sama dengan diskusi kelompok. Pertama-tama, guru meminta siswa untuk duduk berkelompok-kelompok. Masingmasing anggota diberi nomor. Setelah selesai, guru memberikan materi yang akan di diskusikan setelah itu siswa kembai lagi ke kelompok asal. Dan setiap siswa memiliki materi yang berbeda dan mereka sebagai tim ahli mendiskusikan bersama kelompoknya, Guru tidak memberitahukan nomor berapa yang akan berpresentasi selanjutnya. Begitu seterusnya hingga semua nomor mendiskusikan materi yang sudah didapatnya.. Menurut Slavin (2005), metode yang dikembangkan oleh Rushh Frank ini cocok untuk memastikan akuntabilasi individu dalam diskusi kelompok. (Lie. 1994). Setiap anggota dari tim-tim yang berbeda dengan topik yang sama bertemu untuk diskusi (tim ahli) saling membantu sama lain tentang topik yang ditugaskan kepada mereka. Kemudian mereka kembali kepada tim/kelompok asal untuk menjelaskan kepada anggota kelompok yang lain tentang apa yang mereka pelajari sebelumnya pada pertemuan tim ahli.

Berbeda halnya dengan situasi pembelajaran yang terbentuk melalui model pembelajaran Konvensional yang digunakan oleh SD Siumbut-Umbut Kisaran yaitu model pembelajaran Make and Match . Model pembelajaran Make and match juga merupakan salah satu model pembelajaran kooperatif adalah suatu metode pembelajaran dalam pendekatan cooperative learning yang dikembangkan oleh Lena Curran (Zainal, 2013:23). Akan tetapi, model pembelajaran Make And Match membutuhkan koordinasi secara bersamaan dari berbagai aktivitas, membutuhkan perhatian khusus dalam penggunaan ruangan kelas dan peralihan dari seluruh kelas ke kelompok kecil dapat menyita waktu pengajaran yang berharga. Kondisi ini akan mempengaruhi mental siswa didalam melakukan diskusi. Model Make and match memberi waktu kepada para siswa untuk berfikir dan merespons serta saling membantu yang lain. Model pembelajaran jigsaw dan 
Make and match merupakan model pembelajaran yang sama-sama memiliki konsep kooperatif berdiskusi bagi siswa dalam kegiatan pembelajaran.

Akan tetapi secara teknis pelaksanaan kedua pembelajaran tersebut memiliki perbedaan yaitu pada tahap pelaksanaan diskusi, guru dalam meninjau dan mengukur pemahaman siswa secara klasikal. Pada model pembelajaran Jigsaw, kegiatan presentasi hasil diskusi kelompok sudah terlebih dahulu menunjuk kelompok diskusi yang akan tampil sehingga bagi kelompok diskusi siswa yang tidak tampil kemungkinan akan kurang memaksimalkan kegiatan diskusi kelompok. Berbeda halnya dengan model pembelajaran Make and Match, dimana kegiatan presentasi hasil diskusi kelompok dilakukan secara acak oleh guru dengan menilai atas dikusi yang dilakukan sdengan melihat apakah soal dan jawaban itu benar pasangannya. Kemudian sama halnya dengan media, menurut AECT (Association of Education and Communication and Tecnonology), (1997) mengemukakan bahwa media adalah semua bentuk dan saluran yang digunakan dalam proses penyampaian informasi. Kemudian Gagne (Sardiman, 2007:1) menyatakan media adalah berbagai jenis komponen dan lingkungan.

Setelah mengkaji faktor eksternal di atas, faktor internal siswa juga turut menjadi bagian penting didalam menentukan kualitas hasil belajar siswa. Faktor internal adalah faktor yang berasal dari dalam diri siswa seperti komunikasi, motivasi, minat, komunikasi interpersonal dan inteligensi siswa. Dalam hal ini yang akan dikaji adalah faktor komunikasi interpersonal siswa sebagai faktor yang berasal dari dalam diri siswa. Setiap siswa mempunyai cara atau sikap yang berbeda-beda dan hal tersebut selalu dilakukannya dalam belajar. Hal tersebut sesuai dengan beberapa pendapat dari beberapa ahli. Menurut Mulyana (2007), komunikasi interpersonal adalah komunikasi antara orang-orang secara tatap muka, yang memungkinkan setiap pesertanya menangkap reaksi orang lain secara langsung, baik secara verbal maupun non-verbal.

Komunikasi interpersonal adalah suatu proses pertukaran makna antara orang-orang yang saling berkomunikasi. Pengertian proses mengacu pada perubahan dan tindakan yang berlangsung secara terus menerus. Pengertian pertukaran yaitu tindakan menyampaikan dan menerima pesan secara timbal balik

Komunikasi interpersonal ini berkaitan dengan pribadi seseorang yang tentu dipengaruhi oleh pendidikan dan riwayat perkembangannya. Devito (2011:285) mengemukakan efektivitas komunikasi interpersonal dimulai dengan lima kualitas umum yang dipertimbangkan yaitu keterbukaan (openness), empati (empaty), sikap mendukung (supportiveness), sikap positif (positiveness, dan kesetaraan (equality)

Oleh sebab itu, sangatlah penting bagi seorang guru dengan terlebih dahulu memperhatikan karakteristik siswa berdasarkan komunikasi interpersonalnya untuk dapat menentukan model pembelajaran yang tepat agar kegiatan pembelajaran berlangsung menarik dan hasil belajar yang dicapai optimal. Berdasarkan uraian di atas, penulis merasa tertarik untuk melakukan penelitian tentang “ Pengaruh Model Pembelajaran Kooperatif Learning Berbasis Media Interaktif dan Komunikasi interpersonal Siswa Terhadap Hasil Belajar Pendidikan Agama Islam di SD Siumbut-Umbut Kabupaten Asahanr”.

Adapun yang menjadi tujuan dalam penelitian ini adalah untuk memperoleh gambaran tentang pengaruh aplikasi penggunaan model pembelajaran dan komunikasi interpersonal terhadap hasil belajar siswa pada mata pelajaran Pendidikan Agama Islam, sedangkan secara khusus penelitian ini bertujuan untuk mengetahui: (1) Apakah hasil belajar pendidikan agama Islam siswa yang menggunakan model jigsaw lebih tinggi daripada hasil belajar pendidikan agama Islam yang menggunakan model make and match ? (2) Apakah hasil belajar pendidikan agama Islam siswa yang memiliki komunikasi interpersonal tinggi lebih tinggi daripada hasil belajar pendidikan agama Islam yang memiliki komunikasi interpersional rendah? (3) Apakah terdapat interaksi antara model pembelajaran dan komunikasi interpersonal terhadap hasil belajar pendidikan agama Islam siswa.

\section{METODE PENELITIAN}

Lokasi penelitian dilaksanakan di SD Siumbut-Umbut Kisaran Kabupaten Asahan. Waktu penelitian dilaksanakan pada semester genap bulan Maret tahun akademik 2016/2017. Populasi dalam penelitian ini adalah seluruh 
siswa kelas $\mathrm{V}$ pada semester genap yang terdiri dari 3 kelas dengan jumlah 120 siswa.

Penelitian ini menggunakan desain faktorial 2 × 2 sebagai variabel bebas pertama adalah penggunaan model pembelajaran yang dibedakan atas pembelajaran Jigsaw dan pembelajaran Make and match. Variabel moderator yaitu komunikasi interpersonal siswa, dengan pengelompokan komunikasi interpersonal Komunikasi interpersonal tinggi dan komunikasi interpersonal Komunikasi interpersonal rendah.

Tabel 1. Rancangan Faktorial 2 x 2

\begin{tabular}{lll}
\hline Komunikasi Interpersonal & \multicolumn{2}{l}{ Model Pembelajaran } \\
\cline { 2 - 3 } & Jigsaw $\left(\mathrm{A}_{1}\right)$ & Make and Match $\left(\mathrm{A}_{2}\right)$ \\
\hline Tinggi $\left(\mathrm{B}_{1}\right)$ & $\mathrm{A}_{1}, \mathrm{~B}_{1}$ & $\mathrm{~A}_{2}, \mathrm{~B}_{1}$ \\
\hline Rendah $\left(\mathrm{B}_{2}\right)$ & $\mathrm{A}_{1}, \mathrm{~B}_{2}$ & $\mathrm{~A}_{2}, \mathrm{~B}_{2}$ \\
\hline
\end{tabular}

Keterangan:

A : Model Pembelajaran

B : Komunikasi Interpersonal

$\mathrm{A}_{1} \quad$ : Model pembelajaran Jigsaw

$\mathrm{A}_{2}, \quad$ : Model Pembeajaran Make AndMatch

$\mathrm{B}_{1} \quad$ : Komunikasi Interpersonal tinggi

$\mathrm{B}_{2} \quad$ : Komunikasi Interpersonal rendah

$\mathrm{A}_{1}, \mathrm{~B}_{1}$ : Hasil belajar Pendidikan agama Islam mahasiwa yang dibelajarkan menggunakan model jigsaw pada komunikasi interpersonal tinggi.

$\mathrm{A}_{1}, \mathrm{~B}_{1}$ : Hasil belajar Pendidikan agama Islam mahasiwa yang dibeajarkan menggunakan model jigsaw pada komunikasi interpersonal rendah.

$A_{2} B_{1} \quad$ : Hasil beajar siswa yang mempunyai komunikasi interpersonal tinggi dengan menggunakan model pembelajaran Make and Match

$\mathrm{A}_{1} \mathrm{~B}_{2} \quad$ : Hasil belajar siswa yang mempunyai komunikasi interpersonal

$\mathrm{A}_{2} \mathrm{~B}_{2} \quad$ : rendah dengan menggunakan model pembelajaran Make and Match

Teknik analisis data dalam penelitian ini menggunakan analisis deskriptif dan analisis inferensial. Teknik analisis deskriptif dimaksudkan untuk mendeskripsikan data penelitian meliputi mean, median, standar deviasi, modus dan median data. Untuk menguji kebenaran hipotesis yang diajukan dalam penelitian ini, maka teknik analisis data yang digunakan adalah Analisis Varians (Anava) Dua Jalur. Pengunaan teknik ini dengan maksud agar hasil tes akhir yang dicapai oleh subjek penelitian benar - benar karena pengaruh dari perlakuan yang diberikan selama penelitian. Taraf signifikan yang digunakan dalam penelitian ini adalah $\propto=5 \%$. Selanjutnya apabila hasil pengujian menunjukan terdapatnya interaksi maka perlu dilakukan uji lanjut dengan uji Scheffe apabila jumlah siswa (n) tiap sel berbeda atau uji Tuckey apabila jumlah siswa (n) tiap sel sama.

Adapun rumusan hipotesis statistic dalam penelitian ini adalah sebagai berikut :

a. Hipotesis pertama

$\mathrm{H}_{0}: \mu \mathrm{A}_{1 .} \leq \mu \mathrm{A}_{2}$

$\mathrm{H}_{\mathrm{a}}: \mu \mathrm{A}_{1}>\mu \mathrm{A}_{2}$

b. Hipotesis Kedua

$\mathrm{H}_{0}: \mu \mathrm{B}_{1}=\mu \mathrm{B}_{2}$

$\mathrm{H}_{\mathrm{a}}: \mu \mathrm{B}_{1} \neq \mu \mathrm{B}_{2}$

c. Hipotesis Ketiga

$\mathrm{H}_{0}: \mathrm{A}><\mathrm{B}=0$

$\mathrm{H}_{\mathrm{a}}: \mathrm{A}><\mathrm{B} \neq 0$

\section{Keterangan :}

$\mu \mathrm{A}_{1} \quad=$ Rata-rata hasil Belajar siswa model Pembelajaran Jigsaw

$\mu \mathrm{A}_{2} \quad=$ Rata-rata hasil Belajar siswa Model Pembelajaran Make and Match

$\mu \mathrm{B}_{1} \quad=$ Rata-rata komunikasi interpersonal siswa tinggi

$\mu \mathrm{B}_{2} \quad=$ Rata-rata komunikasi interpersonal siswa rendah.

\section{HASIL PENELITIAN}

Uji menggunakan ANAVA dua jalur 
Tabel 1. Uji Anava Faktorial 2 x 2

\begin{tabular}{lllllll}
\hline Sumber varians & dk & JK & RJK & $\mathbf{F}_{\text {hitung }}$ & $\begin{array}{l}\mathbf{F}_{\text {tabel }} \\
(\mathbf{1 , 6 8})(\mathbf{0 , 0 5})\end{array}$ & Ket \\
\hline Model Pembelajaran (A) & 1 & 1007,22 & 1007,22 & 12,94 & 4,00 & Signifikan \\
\hline $\begin{array}{l}\text { Komunikasi Interpersonal } \\
\text { (B) }\end{array}$ & 1 & 922,77 & 922,77 & 11,86 & 4,00 & Signifikan \\
\hline Interaksi (AB) & 1 & 808,73 & 808,73 & 10.39 & 4,00 & Signifikan \\
\hline Galat & 57 & 6611,67 & 77,78 & & & \\
\hline
\end{tabular}

Keterangan:

A : Model Pembelajaran

B : Komunikasi interpersonal

Dk : Derajat kebebasan

JK : Jumlah kuadrat

RJK : Rerata jumlah kuadrat

Bentuk interaksi tersebut dapat dilihat pada gambar 1 berikut.

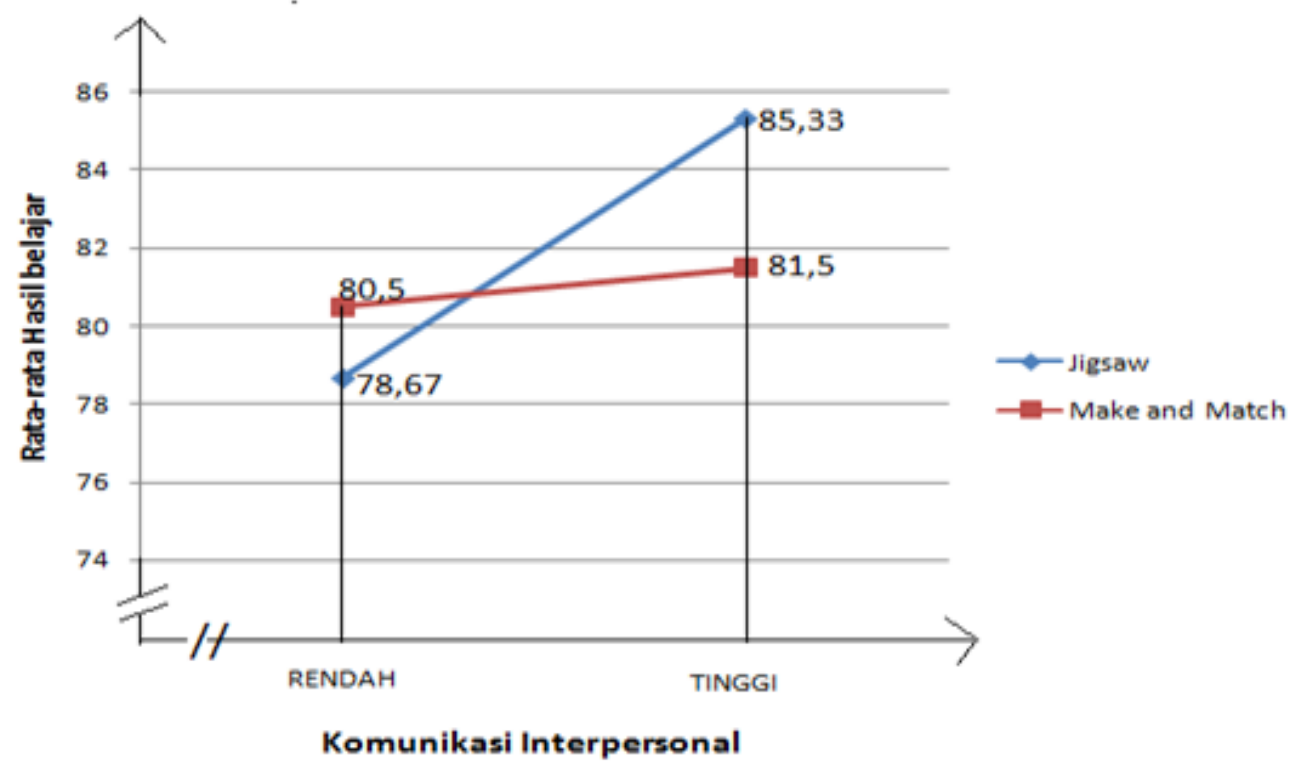

Gambar 1. Interaksi Antara Model Pembelajaran dan Komunikasi Interpersonal Terhadap Hasil Belajar PAI

\section{PEMBAHASAN}

Tujuan utama penelitian ini adalah untuk mendeskripsikan pengaruh Model Pembelajaran dan Komunikasi interpersonal terhadap hasil belajar Pendidikan Agama Islam siswa. Hal pertama yang dilakukan adalah melakukan analisis deskriptif yang bertujuan untuk melihat gambaran hasil belajar siswa. Kemudian dilakukan analisis inferensial terhadap pengaruh tersebut. Berdasarkan hasil pengolahan data, berikut diuraikan berturut-turut tentang deskripsi data masing-masing variabel penelitian, pengujian persyaratan analisis dan pengujian hipotesis.

Hasil pengujian hipotesis pertama Hasil Belajar Pendidikan Agama Islam Kelompok Siswa Yang Diajar Dengan Model Pembelajaran Jigsaw Lebih Tinggi Dibandingkan Hasil Belajar Pendidikan Agama Islam Kelompok Siswa Yang Diajar Dengan Model Pembelajaran Make and Match

Pendidikan Agama Islam mempunyai peran yang sangat penting karena dapat membentuk siswa untuk memiliki mental yang kuat, sehingga dapat mengatasi permasalahan 
dan tantangan yang dihadapi. Perlu perhatian dalam memotivasi siswa untuk dapat mencapai hasil belajar pendidikan Agama Islam yang lebih baik. Pembelajaran pendidikan Agama Islam membutuhkan keteladanan dan suasana yang baik di rumah, sekolah, masyarakat, bangsa dan Negara. Melalui model pembelajaran Jigsaw dan Make and Match tujuan pembelajaran yang terdapat pada pembelajaran Pendidikan Agama Islam diharapkan dapat tercapai. Kondisi pembelajaran yang berpusat pada siswa aktif sangat diharapkan pada pelaksanaan kedua model pembelajaran tersebut.

Temuan penelitian ini juga sejalan dengan hasil penelitian yang dilakukan oleh Hasil penelItian Yueh Min Huang (2013) mengatakan bahwa pendekatan Pembelajaran Kooperatif Berbasis Jigsaw dapat meningkatkan Hasil Belajar siswa di Taiwan... Melalui model pembelajaran yang dapat meningkatkan keaktifan siswa dalam belajar teruji dapat mengoptimalkan hasil belajar siswa. Kondisi berbeda yang terjadi dengan Model pembelajaran Make and Match yang memfokuskan kegiatan pembelajaran pada guru sebagai sumber informasi belajar dan siswa hanya mampu mengetahui sebagian dari materi yang dari guru.

Pengujian hipotesis kedua hasil belajar PAI Kelompok Siswa Yang Memiliki Komunikasi Interpersonal Tinggi lebih Tinggi Dari Hasil Belajar PAI Kelompok Siswa Yang Memiliki Komunikasi Interpersonal Rendah. Temuan penelitian ini telah membuktikan hal tersebut. Bagi siswa yang memiliki komunikasi interpersonal tinggi memposisikan diri sebagai pribadi yang selalu terdorong mencapai prestasi optimal dalam belajar, untuk memperoleh penghargaan tertinggi dari guru terlebih lagi untuk kepuasan diri. Oleh sebab itu, siswa yang memiliki komunikasi interpersonal tinggi memiliki usahan belajar yang lebih dibandingkan dengan siswa yang memiliki komunikasi interpersonal rendah. Siswa dengan komunikasi interpersonal tinggi belajar dengan berfikir dan berbuat. Mereka suka melakukan sesuatu dan mengalami sendiri pengalaman belajarnya. Selain itu mereka mampu mengambil keputusan dengan cerdas mengunakan intlektualitas mereka bukan berdasarkan intuisi dan perasaan. Ciri khas dari siswa yang memiliki komunikasi interpersonal tinggi ini selaras dengan tujuan dari pembelajaran Pendidikan PAI seperti yang diuraikan oleh Al-Abrasy (1985:1) Pendidikan Islam ialah mendidik ahlak dan jiwa mereka, mmenanam rasa keutamaan, membiasakan mereka dengan kesopanan yang tinggi, mempersiapkan untu sesuatu yang suci seluruhnya.

Hal berbeda terjadi pada siswa yang memiliki komunikasi interpersonal rendah dimana siswa dengan komunikasi interpersonal rendah adalah tipe orang yang umumnya mampu menggali opini-opini orang lain. Karena posisinya, mereka ini memiliki beberapa kelemahan umum seperti, cenderung kurang aktif tetapi banyak beride-ide. Mereka adalah tipe pengharap. Keadaan tersebut membuat mereka tidak sanggup melihat dengan arif dan detail jika permasalahan yang dihadapi terlalu banyak. Orang-orang tipe ini cenderung tidak senang memberikan kritik yang keras karena mereka juga tidak suka dikritik.

Dengan memperhatikan ciri khas siswa berdasarkan komunikasi interpersonal belajarnya akan lebih membantu guru untuk menemukan solusi belajar terbaik bagi siswa dalam hal menghindari kejenuhan belajar dan meningkatkan gairah belajar siswa berdasarkan kebutuhan belajarnya. Dari uraian di atas dan didasarkan pada hasil penelitian yang diperoleh dapat disimpulkan bahwa siswa yang memiliki Komunikasi Interpersonal Tinggi memiliki hasil belajar Pendidikan PAI yang lebih tinggi dibandingkan dengan siswa yang memiliki Komunikasi Interpersonal rendah teruji kebenarannya.

Pengujian hipotesis ketiga Terdapat Interaksi Antara Model Pembelajaran dan Komunikasi Interpersonal. Dalam Mempengaruhi Hasil Belajar PAI melalui uji lanjut Scheffe telah diperoleh model pembelajaran yang memiliki interaksi dengan Komunikasi Interpersonal yang lebih positif dan signifikan terhadap hasil belajar Pendidikan Agama Islam siswa.

Berdasarkan hasil analisis uji lanjut diperoleh bahwa hasil belajar Pendidikan Agama Islam siswa yang memiliki komunikasi interpersonal tinggi yang diberi perlakuan dengan model pembelajaran Jigsaw teruji lebih unggul dibandingkan dengan hasil belajar siswa lainnya. Hasil ini membuktikan bahwasanya siswa yang memiliki komunikasi interpersonal tinggi lebih memaksimalkan hasil belajar Pendidikan PAI apabila didukung melalui 
model pembelajaran yang lebih membangkitkan keaktifan siswa dan suasana pembelajaran yang menantang dan menyenangkan seperti yang terjadi dalam perlakuan model pembelajaran Jigsaw. Model pembelajaran Jigsaw lebih mengundang daya tarik belajar siswa dan hal ini merupakan kondisi yang sangat disenangi oleh kelompok siswa yang memiliki komunikasi interpersonal rendah. Mereka lebih tertantang untuk aktif belajar dan melalui model pembelajaran jigsaw memberikan kondisi pembelajaran dengan pengalaman nyata sehingga lebih berkesan bagi siswa dan dapat lebih bertahan lama dalam ingatan siswa.

Temuan penelitian ini sejalan dengan pendapat yang dikemukakan oleh Slameto (2009:54) mengenai faktor-faktor yang mempengaruhi hasil belajar yang digolongkan menjadi dua, yaitu (1) Faktor internal yaitu faktor yang berasal dari dalam diri peserta didik yang meliputi dua aspek, yaitu: (a) Faktor jasmaniah seperti kesehatan dan cacat tubuh dan (b) Faktor psikologis seperti intelegensi, sikap, gaya belajar, minat dan motivasi; (2) Faktor eksternal yaitu faktor-faktor yang yang sifatnya di luar diri peserta didik, faktor ini dibagi menjadi tiga yaitu (a) faktor keluarga seperti cara orang tua mendidik, relasi antar anggota keluarga, suasana rumah, keadaan ekonomi keluarga dan latar belakang kebudayaan; (b) faktor sekolah seperti model pembelajaran, kurikulum, metode belajar, tugas rumah; dan (c) Faktor masyarakat. Dengan memadukan faktor model pembelajaran yang tepat untuk berinteraksi dengan komunikasi interersonal, maka diperoleh hasil belajar yang optimal. Model Pebelajaran Jigsaw teruji cocok diterapkan pada siswa yang memiliki komunikasi interpersonal tinggi dikarenakan kegiatan belajar yang disajikan dapat memacu semangat belajar siswa melalui permasalahan belajar yang nyata dan pembentukan pengetahuan berdasarkan cara siswa. Dan Make and Match ternyata tidak berpengaruh signifian. Hal ini berarti antara pemilihan mode pembelajaran dan dengan memperhatikan komunikasi interpersonal belajar siswa yang memiliki komunikasi interpersonal berbeda akan mengoptimalkan hasil belajar PAI siswa.

\section{PENUTUP \\ Simpulan}

Berdasarkan hasil penelitian dapat ditarik kesimpulan bahwa terdapat interaksi yang positif dan signifikan antara Model Pembelajaran dan Komunikasi Interpersonal siswa dimana Model Pembelajaran Jigsaw dapat diterapkan pada siswa yang memiliki Kounikasi interpersonal tinggi dalam mengotimalkan hasil belajar siswa.

\section{DAFTAR PUSTAKA}

Anderson,O.W.dan Karthwohl,D.R. (2001). A Taxaonomy for Learning, Teaching and Assessing. New York: Addison wesley Longman,Inc

Arends, R (1997), Classroom Instructional and Management, MeGraw Hill Book, New York.

Arikunto, S. (2005). Dasar-Dasar Evaluasi Pendidikan. Jakarta: Bumi Aksara

Sanjaya,W. (2008). Strategi Pembelajaran Berorentasi Standar Proses Pendidikan. Jakarta : Kencana Prenada Media Group

Slameto. (2009). Belajar dan Faktor-faktor yang mempengaruhinya. Jakarta: PT. Asdi Mahasatya

Slavin, Robert. (2005). Cooperative Learning : Theory, Research And Practice. London: Allymand Bacon

Sudjana. (2005). Metode Statika. Bandung: Tarsito

Sudjana, Nana. (2005). Penilaian Hasil Proses Belajar Mengajar. Bandung: Penerbit PT Remaja Rosdakarya

Suharsimi, Arikunto (2003) Prosedur Penelitian Suatu Pendekatan Praktik. Jakarta: Rineka Cipta.

Suprijono, Agus. (2010) Cooperative Learning: Teori dan Aplikasi PAIKEM. Yogyakarta: PT Pustaka Pelajar

Trianto. (2009). Mendesain Model Pembelajaran Progresif. Bandung: PT Angkasa

Trianto. (2007) . Model-model Pembelajaran Inovatif Berorientasi Konstruktivistik. Jakarta: Prestasi Pustaka Publisher 